TRINDADE, Cláudia Moraes. Doenças, alimentação e resistência na penitenciária da Bahia, 1861-1865. História, Ciências, Saúde - Manguinhos, Rio de Janeiro, v.18, n.4, out.-dez.2011, p.1073-1093.

\title{
Doenças, alimentação e resistência na penitenciária da Bahia, 1861-1865*
}

\section{Diseases, food, and resistance in the Bahia penitentiary, 1861-1865}

\section{Cláudia Moraes Trindade}

Professora do curso de história/ Centro Universitário Jorge Amado. Avenida Luís Viana, 6775 41745-130 - Salvador - BA - Brasil claudiat@ufba.br

Recebido para publicação em junho de 2010. Aprovado para publicação em maio de 2011
Resumo

Apresenta um estudo sobre as doenças e as condições de alimentação dos presos da Casa de Prisão com Trabalho em Salvador, Bahia, nos primeiros anos de seu funcionamento. Analisa suas estratégias em busca de tratamento médico e de uma alimentação digna, e destaca também como os presos se apropriavam das novas normas oficiais para resistir e conquistar espaços de respiração dentro do novo modelo de aprisionamento pretendido pela primeira penitenciária da Bahia. Demonstra que nem mesmo privados de necessidades tão básicas, como as relacionadas a saúde e alimentação, os presos se tornaram vítimas passivas do novo sistema prisional; pelo contrário, atuaram ativamente na construção da própria história.

Palavras-chave: presos; doenças; alimentação; história da prisão; Bahia; século XIX.

\section{Abstract}

This study on prisoners' diseases and food conditions in the early days of operation of the Casa de Prisão com Trabalho (labor penitentiary) in Salvador, Bahia, analyzes prisoner strategies for obtaining medical treatment and decent food. In their resistance and struggle to achieve more breathing room within the new prison model, which authorities hoped to implement at Bahia's first penitentiary, prisoners themselves took advantage of the new official norms. Even when deprived of such basic necessities as health and food, prisoners were not passive victims of the new prison system but instead engaged actively in the construction of their own history.

Keywords: prisoners; disease; food; prison history; Bahia; nineteenth century. 
$\mathrm{D}$ urante o século XIX, o Império do Brasil construiu as suas primeiras penitenciárias, denominadas, na época, casas de correção ou casas de prisão com trabalho, como foi o caso específico da Bahia. ${ }^{1}$ Embora a prisão seja muito mais antiga, foi no século XIX que as instituições passaram a ter o objetivo de internar e recuperar o sentenciado, e não apenas de castigá-lo, como acontecia no antigo regime prisional instaurado pelos portugueses no início da colonização no Brasil. A partir da década de 1820, o Brasil deu andamento à reforma do seu aparato carcerário seguindo os passos de países como a França e os Estados Unidos, que iniciaram suas reformas prisionais no final do século XVIII. No início do século seguinte, esses países já contavam com modernas penitenciárias inspiradas na arquitetura panóptica, criada pelo inglês Jeremy Bentham. ${ }^{2}$ Os sistemas de Auburn e da Pensilvânia, desenvolvidos nas penitenciárias norte-americanas, dividiram a opinião de reformadores de vários países que aderiram às ideias penitenciárias, incluído o Brasil. Ambos os sistemas se utilizavam de normas disciplinares por meio do isolamento, do trabalho e da religião. ${ }^{3}$ No caso do Brasil, os estudiosos e autoridades locais tiveram que adaptar as ideias desenvolvidas na França, Inglaterra e Estados Unidos à realidade do país, uma sociedade escravista, em todo o seu vigor, em meados do século XIX.

Esse processo de adaptação dos modelos estrangeiros deu um caráter particular às instituições prisionais, assim como a todas as outras que se ergueram no Oitocentos, como asilos, hospitais, colégios, cemitérios etc. ${ }^{4} \mathrm{~A}$ reforma prisional teve suas particularidades até mesmo entre as províncias, pois cada uma delas reorganizou as cadeias e implantou sua penitenciária de acordo com os interesses das elites, da política e das necessidades locais de um modo geral. No caso da Bahia, por exemplo, a penitenciária não recebia escravos nem praticava pena de açoites, enquanto em outras províncias, como Rio de Janeiro e São Paulo, as autoridades adaptaram suas casas de correção para também prender e castigar escravos, o que fugia totalmente das doutrinas defendidas pelos reformadores internacionais. ${ }^{5}$

Neste artigo, pretendo analisar as condições de saúde e alimentação dos presos da penitenciária da Bahia nos primeiros cinco anos de funcionamento. Esse período inicial é estratégico para entendermos sua reação frente ao novo modelo de aprisionamento recémimplantado na Bahia. Esses presos vieram transferidos de outras cadeias da cidade onde não havia nenhum projeto de reabilitação. $\mathrm{O}$ momento era de expectativa para ambas as partes: presos e autoridades. Por outro lado, a penitenciária, depois de quase três décadas de construção e debates sobre sua implantação, foi inaugurada com as obras ainda incompletas. As oficinas de trabalho, tão importantes no processo de reabilitação, só foram inauguradas em 1865. Não havia nem mesmo uma enfermaria própria. Numa das reivindicações os presos disseram que a Casa de Prisão com Trabalho era como 'uma figa' para os governantes baianos (Neves, 1862). Esse seria mais um indício de que os presos tinham ideia do significado da prisão-modelo para as autoridades e disso se utilizaram para protestar.

\section{Inauguração da Casa de Prisão com Trabalho: modelo e realidade}

No dia 31 de outubro de 1861 uma movimentada operação alterou a rotina prisional da cidade de Salvador. A cadeia do Aljube estava sendo desativada. Os presos sentenciados 
seguiram para a Cadeia do Barbalho, e os que aguardavam julgamento, ou detidos sob custódia, foram encaminhados para a Cadeia da Correção. ${ }^{6} \mathrm{O}$ contato com o público durante o trajeto, a pé, provavelmente despertou a curiosidade dos transeuntes. Muitos talvez desconhecessem as mudanças que estavam ocorrendo na organização prisional da cidade. Não era o caso dos presos, pois esses estavam sempre atentos às decisões que lhes diziam respeito. Enquanto alguns chegavam àquelas duas prisões, outros saíam para a Casa de Prisão com Trabalho, que estava sendo inaugurada naquele mesmo dia (Cunha, 1861). ${ }^{7}$ Até os funcionários foram remanejados. O carcereiro João Bernardo da Cunha fez a entrega da "Cadeia da Correção e de tudo que lhe é relativo a João Caetano Martins" para, a partir de então, assumir a carceragem da Casa de Prisão com Trabalho, cumprindo a ordem do chefe de polícia, Pereira da Cunha (Cunha, 1861). Durante os meses de novembro e dezembro, a nova penitenciária foi ocupada gradativamente. Alguns presos, entre os que deveriam ser transferidos, se encontravam doentes no Hospital da Caridade. ${ }^{8}$ Esses, ao receberem alta, seguiram diretamente para a nova instituição que, ao findar aquele ano, já contava com 115 internos.

A falta de recursos para conclusão das obras e contratação de mais funcionários estimulou o presidente da província, Joaquim Antão, a expedir um ato, em 20 de junho de 1862, rebaixando a categoria da instituição de Casa de Prisão para a de cadeia comum "visto que esta Assembleia na sua última reunião nada havia deliberado acerca das despesas que se fazem necessárias para o estabelecimento de uma prisão com trabalho" (Albuquerque, 1863, p.15). Com essa determinação, a prisão passou a chamar-se Cadeia da Conceição9, situação que foi logo revertida pelo seu sucessor, Antonio Coelho de Sá e Albuquerque. Vejamos a seguir um trecho de sua fala de abertura na Assembleia Provincial.

\footnotetext{
A prisão aludida foi construída com destino a ser casa de prisão com trabalho ... estou no propósito de prosseguir nas obras que são ainda necessárias para que sejam realizadas as vistas filantrópicas daqueles que lançarão os fundamentos de tal instituição. Rogo-vos, pois, que me autorizem não só para a continuação das despesas para isso necessárias, como também para a nomeação dos empregados que os estabelecimentos de tal gênero requerem (Albuquerque, 1863, p.15).
}

Albuquerque (1863, p.15) visitou a Casa de Prisão com Trabalho para uma inspeção e declarou ter observado "o aspecto enfermo dos presos" dizendo que não podia esperar outra coisa a considerar "as péssimas condições higiênicas que assaltam a vista do observador", confirmando assim a falta de estrutura da nova prisão. Esse tipo de preocupação dos governantes e das autoridades policiais era comum no período pós-inauguração. O empenho de Albuquerque trouxe resultados positivos. A lei provincial 909, de 1862, autorizou o governo da província a tomar as medidas necessárias para que a Cadeia da Conceição retornasse à categoria de penitenciária, o que ocorreu em 1863. Em 14 de outubro daquele mesmo ano foi implantado o regulamento oficial. Na sua curta administração, de 30 de setembro de 1862 a 15 de setembro de 1863, Antonio Coelho Albuquerque deixou registrada sua importante contribuição à história da penitenciária baiana.

Num estudo sobre os primeiros presos que ocuparam a Casa de Prisão com Trabalho, no período de 1861 a 1865, pude identificar o perfil dos indivíduos que as autoridades 
baianas pretendiam reabilitar e inserir no mundo do trabalho. Num levantamento de 111 presos, dos que foram selecionados pelo chefe de polícia para ocupar a nova penitenciária, constatei que se tratava, em sua maioria, de homens livres, pardos e negros, sentenciados à prisão com trabalho por crime de morte ou furto. Somente homens livres e libertos poderiam ser condenados à pena de prisão com trabalho; mesmo assim é quase nula a presença de libertos na penitenciária. Eles continuaram a cumprir pena na Cadeia da Correção para onde também eram mandados os escravos detidos. No grupo analisado, havia somente 16 mulheres. Foi muito reduzida a presença feminina na penitenciária da Bahia, sendo que, após 1865 , a instituição passou a receber somente homens..$^{10}$ Os poucos escravos que localizei na Casa de Prisão com Trabalho eram sentenciados à pena de morte e aguardavam ali o resultado da petição de graça feita ao imperador. No período pesquisado não encontrei nenhum caso de execução, situação que se explica, em parte, pelo grande número de deferimentos dos pedidos de graça por parte do imperador (Chalhoub, 1990). O Código Criminal do Império, promulgado em 1830, deu continuidade às práticas de punições do período colonial, como a pena de açoites, de galés e de morte, aplicadas a escravos ou homens livres de forma diferenciada. ${ }^{11}$ Essas penas coexistiram com o novo conceito de punição, baseado na privação de liberdade e na reabilitação do criminoso, representado pela prisão com trabalho. Vale lembrar que nem mesmo no berço da reforma prisional - França e Estados Unidos -, a construção das penitenciárias significou uma ruptura com as punições típicas do antigo regime, uma vez que a pena de morte e a deportação continuaram a ser aplicadas. ${ }^{12}$

Alguns meses após a inauguração da Casa de Prisão com Trabalho, os presos escreveram uma correspondência coletiva para o presidente da província. A carta, que trazia graves denúncias contra a administração, tinha a assinatura do João Byspo das Neves, um pardo de 31 anos que cumpria pena por crime de morte (Relação de presos..., s.d.). Ao lado de sua assinatura, escreveu: "por mim e meus companheiros". Os presos sempre procuravam os meios para denunciar ao mundo exterior as práticas cruéis a que geralmente estavam sujeitos. ${ }^{13}$ Entre as muitas reclamações, estava a questão da alimentação.

Esta comida tão grosseira, que dizem que assim marca hum regulamento q[eu] as comidas sejam parcas e saudaveis, porem carne podre sem lavar-se bacalhao da mesma forma a quem poderá assim viver! Ninguém pode queixar-se, morra embora ao menos sucede q[ue] nossas queixas ao adm[inistrad]or este fallou ao Sr. Comendador José de Barros Reis, um dos membros da Comição inspectora desta m[es]ma casa, repondeo q[ue] desse bacalhao, e depois muita agoa á beber (Neves, 1862).

Interessante é que, pouco antes dessa denúncia, o chefe de polícia, João Antonio de Araujo Freitas Henriques, esteve na penitenciária vistoriando as instalações, acompanhado dos membros da comissão inspetora da prisão. ${ }^{14}$ No seu relatório, Henriques pareceu bastante satisfeito, contrariamente às queixas dos presos e às impressões do presidente da província, Antonio Coelho Albuquerque, por ocasião de sua visita, conforme vimos. Entre outras considerações, Henriques disse ter encontrado "tudo no maior asseio e regularidade que se podia esperar no estado, em que se acha o dito edifício, ainda por concluir, e no pouco tempo que faz, que para ali foram removidos os presos, que lá se conservam". Disse ter 
visitado todos os presos e que nenhum deles teria feito qualquer reclamação. Além do mais, teria presenciado a chegada do jantar, atestando que os alimentos eram "de primeira qualidade" (Chefe de polícia..., 1861).

Os presos podem não ter protestado diretamente a Henriques, mas alguns dias antes da sua visita a comissão inspetora relatou em ata que o preso Querino Dias da Silva reclamou estar doente devido à péssima qualidade da comida que, segundo ele, era "distribuída aos presos sempre fria, e fora de tempo oportuno, ocasionando graves desarranjos à saúde". Além disso, o médico teria negado a sua doença, deixando-o sem tratamento (Ata..., 1861). Querino era um negro de aproximadamente 47 anos, viúvo, e sapateiro. Foi sentenciado pelo júri de Caitité, em 17 de abril de 1859, a 14 anos de prisão por crime de morte (Cento e setenta e dois..., s.d.). A comissão inspetora solicitou ao administrador que mandasse o médico examiná-lo novamente, "a fim de se mudar a competente guia e ser recolhido ao hospital de caridade, no caso de se reconhecer a existência da moléstia de que se queixa, e parece sofrer" (Ata..., 1861). Não localizei o que deliberou o médico naquela ocasião. Se Querino estava realmente doente, é certo que buscou meios para ser tratado. Se não estava, é provável que ele estivesse tentando ser removido para o hospital onde seria mais fácil tentar a fuga ou tratar de algum negócio particular, como alguns presos costumavam alegar. Tive notícia novamente de Querino em 1865, quando passou três dias internado devido a uma bronquite. Conforme a irmã superiora, ele mesmo teria pedido a sua alta (Irmã superiora..., 1865). Querino continuou lutando para tratar de sua saúde, pois uma prescrição médica, datada de alguns meses depois, receitava para ele "provisoriamente a alimentação de carne verde" (Chefe de polícia..., 25 out. 1865). Em 30 de outubro de 1865, Querino solicitou uma audiência com o chefe de polícia, "a fim de declarar os seus sofrimentos" (Silva, 1865). Não tive informação sobre o resultado do encontro, agendado para o dia 3 de novembro, mas no dia 8 daquele mês Querino foi novamente internado no hospital (Chefe de polícia..., 8 nov. 1865). Talvez tenha sido este o seu pedido ao chefe de polícia.

\section{As doenças}

O caminho percorrido por Querino - Casa de Prisão/Hospital/Casa de Prisão - tornou-se uma rotina para muitos presos. Em outubro de 1862, cerca de 7\% dos presos, incluindo as mulheres, se encontravam no hospital. Em 1863 essa parcela subiu para 12,8\% (Mapa numérico..., 1862). ${ }^{15}$ Para 1864 não encontrei nenhum desses mapas, mas os atestados médicos demonstraram que a movimentação continuava crescente, pois num único atestado o doutor José Eduardo Freire de Carvalho encaminhou nove presos para internamento hospitalar. No mês de outubro de $1865,16,4 \%$ dos presos foram remetidos para internamento no hospital, enquanto $11,36 \%$ receberam alta médica. ${ }^{16}$ Ainda para 1865, levantei 268 ocorrências entre internamentos e altas, correspondentes à movimentação de 119 presos (Diversas guias..., s.d.). Das 268 ocorrências, 179 informaram a causa do internamento ou da alta; no entanto, alguns casos não me parecem confiáveis, pois registram para o mesmo preso duas doenças diferentes, uma na guia de internação e outra na alta. Há casos de um preso ter várias ocorrências. Um exemplo é Manoel Mariano Pereira, que, entre fevereiro e 
outubro de 1865, teria sofrido várias enfermidades como doenças de pele, bronquite, conjuntivite, indigestão e dores no corpo (Diversos ofícios..., fev.1865-set.1865; Diversas autorizações..., mar.1865-out.1865). ${ }^{17}$ Outra questão é que a variedade de doenças atestadas nas guias descarta a possibilidade de uma epidemia, como o cólera ou a febre amarela. Esta última teve o seu mais grave surto em Salvador em 1849 e 1850. Depois disso, tornou-se endêmica, aparecendo todos os anos em janeiro e fevereiro. Novos surtos ocorreram na cidade em 1873 e 1880. Vale ressaltar que das 201 pessoas atingidas pela febre amarela, na sociedade mais ampla, em 1860, apenas seis eram brasileiras. Em 1862, os brasileiros perfaziam o número de 13 num total de 292. Europeus e norte-americanos foram os mais atingidos. Esses números indicam que a prisão ficou a salvo da febre amarela no período estudado. Já a epidemia do cólera assolou grande parte de população baiana em 1855 e 1856 (Nascimento, 1986).

Tabela 1: Causas de internamento dos presos (1865)

\begin{tabular}{lrr}
\hline Doenças & no & \% \\
\hline Sistema respiratório & 40 & 14,9 \\
Sistema digestório & 35 & 13,1 \\
Variadas & 25 & 9,3 \\
Infectoparasíticas & 21 & 7,8 \\
Nutricionais & 16 & 6,0 \\
Sistema geniturinário & 14 & 5,2 \\
Reumáticas & 13 & 4,9 \\
Ulcerações & 8 & 3,0 \\
Acidentes ou violência & 4 & 1,5 \\
Pele & 3 & 1,1 \\
Não informa & 89 & 33,2 \\
\hline Total & $\mathbf{2 6 8}$ & $\mathbf{1 0 0 , 0}$ \\
\hline
\end{tabular}

Fontes: Diversos ofícios..., s.d.-b

As doenças respiratórias lideram a lista com quarenta casos, sendo 33 de bronquite, dois de asma, um de pneumonia, um de neuralgia, um diagnosticado como 'sofrendo do pulmão' e dois de pleurodinia, dor reumática nos músculos das costas, e um de laringite. Eram doenças ocasionadas pelo ambiente frio e úmido das celas em que a maioria dos presos permanecia em tempo integral, situação que começou a mudar a partir de 1865, com a inauguração das oficinas. Na época das chuvas, certas áreas da prisão ficavam submersas, tornando o ambiente mais propício a essas doenças. ${ }^{18}$

As doenças do sistema digestório aparecem em número de 35, representadas por 13 casos de constipação de ventre, sete de embaraço gástrico, dois de indigestão, quatro de gastrite, quatro de diarreia, um de hepatite, um de hemorroidas, um de dispepsia, um de distúrbio do aparelho digestivo e um de enteralgia ou dor intestinal. Essas doenças poderiam estar relacionadas à má alimentação, seja no que diz respeito ao estado de conservação dos alimentos ou à carência de vitaminas e proteínas. Segundo um texto da Gazeta Médica de 1869, os casos de afecções gastrointestinais tinham aumentado no Hospital da Caridade, sendo os presos da Cadeia da Correção e da Casa da Prisão com Trabalho os mais afetados, seguidos da população pobre em geral (Rios, 2001, p.135). 
Em terceiro lugar estavam as doenças infectoparasíticas, com 21 ocorrências. Entre elas, dez casos de febre intermitente e um de sezões, expressões utilizadas para definir a malária. É provável que a incidência da malária estivesse relacionada ao terreno pantanoso que circundava a penitenciária, sendo o acúmulo de água salgada e água doce o ambiente perfeito para a proliferação do mosquito transmissor da doença. A tuberculose aparece em seis casos, sendo quatro de hemoptise, um de tísica pulmonar, um de tubérculo, um designado como 'moléstia do peito' e um tubérculo mesentérico ou intestinal. Esses eram apenas alguns dos nomes atribuídos à tuberculose naquela época. Doença de grande incidência na Bahia, onde as péssimas condições de moradia, somadas à alimentação de baixo valor nutritivo, aumentavam as chances de contrair essa e outras doenças de igual gravidade (Barreto, Aras, 2003). Nessa mesma categoria localizamos dois casos de varíola e um de febre tifoide. A varíola, nessa época, se encontrava, de certo modo, controlada devido à existência de vacina. Constatei, aliás, que os presos eram vacinados (Chefe de polícia..., 16 ago. 1865). A febre tifoide, ou febre 'tífica', era uma doença ocasionada por água e alimento contaminados e falta de saneamento básico. Alguns médicos diagnosticavam a febre tifoide como uma forma mais branda do tifo, mas eram doenças consideradas distintas. $\mathrm{Na}$ época, existia muita dificuldade em diagnosticar com precisão os diferentes tipos de febre, uma vez que elas se apresentavam, quase sempre, com os mesmos sintomas, a saber: "febre aguda com calafrios, depressão, fraqueza, dores de cabeça, delírio e erupções" (Karasch, 2000, p.225-226). Em 1924, a Bahia enfrentou uma epidemia de febre tifoide, e o médico Edgar de Cerqueira Falcão atribuiu sua principal causa ao consumo de água contaminada. Já o tifo epidêmico, também conhecido como 'febre da prisão' é transmitido pelo piolho que carrega a bactéria Rickettsia prowazekii (Oficina Sanitária Latinoamericana, 1930, p.894).

As doenças do sistema geniturinário aparecem em número de 14, com cinco casos de sífilis, cinco de estreitamento uretral, um de cancro venéreo, um de hidrocele e um de dartro no escroto. Segundo Karasch (2000), a maioria das doenças do aparelho genital e urinário não era identificada na época, e, caso fosse de origem venérea, era denominada genericamente sífilis. A dificuldade de reconhecimento dessas doenças sugere que havia mais casos, diagnosticados em outras categorias. É possível que muitos presos chegassem doentes à prisão. A tuberculose, por exemplo, poderia estar entre esses casos, por ser uma doença endêmica, na época, assim como as doenças do sistema geniturinário. Por outro lado, a falta de higiene das instalações carcerárias contribuía para o contágio.

No grupo das doenças nutricionais localizei 16 casos, sendo 14 de anemia, um de ambliopia ou perda da visão, e outro de ascite, acúmulo de líquido na cavidade abdominal. Retomarei as doenças nutricionais adiante, quando tratar da alimentação dos presos. Em seguida, na categoria das doenças reumáticas, localizei 13 casos de reumatismo, e entre os casos de ulcerações constam oito ocorrências, sendo quatro de ulcerações na boca, uma na virilha, um abcesso no pescoço, uma fístula lacrimal e outra sem especificação de local. Na categoria classificada como acidentes ou violência, constam quatro casos, sendo duas contusões no tórax, uma no dedo da mão e outra sem especificação de local. Esses casos podem indicar o uso de violência física contra os presos, quer de funcionários quer de outros presos. As doenças de pele somam três. Um caso de impigem frontal, um de sarna e um de dartro. 
Por fim, a categoria que denominei doenças variadas, com o total de 24 casos, sendo seis de conjuntivite, três de extração de dente, três de cárie dentária, três de otite, dois de odontalgia, duas febres de vacina e o restante, casos únicos de dores somáticas, dores de cabeça, gânglio cervical, cólica uterina e febre efêmera. Entre essas doenças, aparentemente mais comuns, é provável que estejam também os casos de simulação que tanto preocupavam os dirigentes da prisão. Fingir-se de doente era um tipo de estratégia muita utilizada pelos presos e bastante conhecida por médicos e administradores de prisão.

A simulação de doenças não era uma prática exclusiva da prisão baiana. Na penitenciária da Corte, por exemplo, o movimento da enfermaria era intenso, muito dele devido ao fato de os presos se fingirem de doentes. Segundo relatou o diretor, Antonio José de Miranda Falcão, em 1855, grande parte dos presos que se encontravam na enfermaria não tinha doença alguma ou sofria de 'incômodos' que não justificavam a suspensão das atividades laborais. Falcão acreditava que os presos simulavam doenças para evitar o trabalho nas oficinas. O doutor Almeida Vale, médico daquela instituição, afirmou que essa prática era comum em todas as prisões e chamou a atenção para os casos curiosos de doenças que apareciam nessas circunstâncias. Naquela época, as oficinas de trabalho já funcionavam regularmente na penitenciária (Pessoa, 2000).

Com relação aos presos internados no Hospital da Caridade de Salvador, o provedor da Santa Casa de Misericórdia observou que o referido hospital também servia "de refrigério a muitos presos, que para ficarem a seu cômodo dão-se por doentes, sem realmente o estarem" (Leite citado em Rios, 2001, p.124). Em 1860, o preso Manuel Marinho Pires, um dos casos de presos com várias internações, foi alvo de indignação do doutor Possivanio Vieira dos Santos, médico interno do Hospital da Caridade. Segundo ele, o preto Manuel Marinho Pires chegou ao hospital com uma guia do carcereiro da Cadeia da Correção e, ao passar por um 'escrupuloso' exame médico, Manuel confessou que de "nada sofria, e vinha somente para com mais facilidade tratar de um negócio" (Santos, 1860). Em 1862, o histórico de Marinho deve ter motivado o chefe de polícia a recomendar ao administrador que ele fosse escoltado "com todas as cautelas e segurança" e que deixasse ciente os médicos "de que há suspeitas que o dito preso a pretexto de moléstia procura ocasião de evadir-se" (Henriques, 24 abr. 1862). Para desespero das autoridades policiais e dos médicos, isso não ocorria somente com Marinho. Em outra ocasião, o chefe de polícia João José de Oliveira Junqueira (1865) autorizou o internamento de três presos, recomendando ao administrador que um deles, Manoel Joaquim Bezerra, só fosse mandado para o hospital em caso de extrema necessidade. Manoel era branco, natural de Pernambuco, tinha 42 anos, viúvo e fora condenado por furto de animais (Carcereiro..., 1865). Em 1868, quando a Casa de Prisão já contava com sua própria enfermaria, Bezerra continuava desafiando a administração. Dessa vez o administrador reclamava do seu comportamento na enfermaria da penitenciária, dizendo que Bezerra caluniava os presos doentes pelo seu "mau gênio e falso camarada" que era (Silva, 12 fev. 1868). Nem o passar do tempo, tampouco os castigos, fazia com que os presos se comportassem de acordo com a vontade dos dirigentes da prisão.

Em agosto de 1862, Manuel Cipriano de Freitas enviou uma petição para o médico solicitando o seu internamento no hospital. O pedido foi negado pelo médico, que alegou 
não ter encontrado motivo para tal procedimento, do contrário "já o teria remetido". O médico também alertou que "o mencionado preso há muito tempo mostra desejos de ser recolhido ao Hospital protestando sempre motivos, que ao meu ver tem sido simulados" (Carvalho, 25 ago. 1862). ${ }^{19}$ Em 1865, encontrei quatro internações de Manuel Cipriano, sendo uma delas autorizada por aquele mesmo médico. A primeira foi devido a uma bronquite e as outras três por hemoptise, uma das denominações da tuberculose. Consta que, em setembro daquele ano, ele teria recebido alta por estar curado (Irmã superiora..., 1865). A cura de Manoel é questionável, salvo se houve algum erro no seu diagnóstico. É pouco provável, naquela época, que uma pessoa tuberculosa chegasse à cura tão rapidamente.

Quanto aos falecimentos, encontrei seis óbitos entre os 119 presos doentes, ou seja, uma taxa de mortalidade de 5\% para 1865 (Diversos ofícios..., s.d.-a). Divergindo desse número, o relatório do administrador interino da penitenciária, Manoel Silva, informou que no período de 1863 a 1865 foram internados 137 presos e desses faleceram 29, o que representa uma taxa de mortalidade de $21,16 \%$, uma média de $7 \%$ ao ano. Não localizei casos de suicídio, somente algumas tentativas que, às vezes, resultavam em privilégios, o que poderia estimular outros a atentarem contra a própria vida. O preso Gustavo Peres Valença golpeou-se no pescoço com a intenção de suicidar-se. Ferido, foi colocado em "uma das melhores células" com o direito de sair, diariamente, para caminhar na galeria, além de receber a visita do médico para os curativos (Chefe de polícia..., 5 set. 1865).

\section{Alimentação}

A Tabela 2, transcrita na íntegra, refere-se à alimentação diária dos presos, fornecida pela Santa Casa de Misericórdia. A comida era preparada na cozinha da penitenciária, conforme observação feita na parte inferior da tabela, e distribuída aos presos com base na quantidade individual indicada. Na mesma tabela, de acordo com o regulamento, constam apenas duas refeições diárias, diferindo dos costumes alimentares da época. Na Casa de Correção da Corte, por exemplo, três refeições diárias eram garantidas, sendo o almoço às oito horas, o jantar ao meio-dia e o horário da ceia variava, a depender da época do ano (Brasil, 1850). ${ }^{20} \mathrm{Na}$ Casa de Prisão com Trabalho a ceia não constava da tabela, sendo o almoço servido às sete horas, e o jantar às duas horas da tarde (Regulamento..., 1863, p.10). ${ }^{21}$

A Tabela 2 indica que a dieta era composta de pão, açúcar, café, farinha de mandioca, bacalhau, carne-seca, feijão, azeite e vinagre. Eram itens normalmente consumidos pelos baianos, que, a depender de suas condições financeiras, os complementavam com outros alimentos. O bacalhau, importado de Portugal, era o prato da sexta-feira, e muito apreciado pela população. A farinha de mandioca e o feijão eram de produção local e utilizados no preparo de vários pratos. A carne-seca era trazida do Rio Grande do Sul, pois a produção local era insuficiente e de baixa qualidade. $\mathrm{O}$ vinagre era muito utilizado na conserva de alimentos, o azeite de oliva e a farinha de trigo eram importados e também amplamente consumidos. O café e o açúcar eram produzidos e consumidos no mercado interno, além de ser produtos de exportação (Mattoso, 1978). Até 1801, a carne-seca era pouco consumida no hospital da Santa Casa da Misericórdia, e a partir de 1802 seu consumo se teria regularizado, sem razão aparente (Mattoso, 1978). 
Tabela 2: Tabela alimentar dos presos

\begin{tabular}{lll}
\hline Dias da semana & Designações das comidas & Quantidade e qualidade dos gêneros* \\
\hline Domingo & Almoço & $\begin{array}{l}1 \text { pão de } 6 \text { onças } \\
1 / 2 \text { onça de café }\end{array}$ \\
& & 1 onça de açúcar \\
& Jantar & Um décimo de quarta de farinha \\
& Lenha & \\
\hline Quarta-feira & Almoço & Como no domingo \\
& Jantar & Meia libra de bacalhau \\
& & Um vigésimo de feijão \\
& & Um décimo de farinha \\
& Lenha, azeite e vinagre \\
\hline Segunda-feira, & Almoço & Como no domingo \\
quinta-feira & & \\
& Jantar & Meia libra de carne de charque \\
& & Um vigésimo de feijão \\
& & Um décimo de farinha \\
\hline Sexta-feira e sábado & Almoço & Como no domingo \\
& Jantar & Como na quarta-feira \\
\hline
\end{tabular}

Observação: Da quantia designada para lenha pode sair a que for necessária para toucinho, manteiga e adubo, por ser a comida cozinhada em comum.

Fonte:Tabela..., 1869.

* 1 onça $=28,35 \mathrm{~g} ; 6$ onças $=170 \mathrm{~g} ; 1 / 2$ onça $=14,17 \mathrm{~g} ; 1 / 2$ libra $=453,60 \mathrm{~g} ; 1$ quarta de farinha $=5,50 \mathrm{~kg} ; 1 / 10$ de quarta de farinha $=550 \mathrm{~g} ; 1 / 20$ de quarta de feijão $=275 \mathrm{~g} ; 1$ alqueire para medida de cereais vale 40 litros $=22 \mathrm{~kg}$.

Para Mary Karasch, o motivo de os senhores alimentarem seus escravos com carne-seca, toucinho e bacalhau não estava relacionado apenas ao preço, e sim à facilidade do transporte e do armazenamento desses itens, uma vez que poderiam ser guardados por até 12 meses sem prejuízo algum (Karasch, 2000). É possível que essa facilidade de armazenamento tenha influído na escolha alimentar para os presos, uma vez que os alimentos eram entregues na penitenciária, guardados na despensa e gradativamente preparados na cozinha. Vale dizer que os itens da Tabela 2 também podiam ser encontrados na mesa da população, tanto do pobre como do rico, com a diferença de que na deste último eram complementados com gêneros mais caros, como carne fresca, frutas, verduras, queijos, leite, geleias, entre outros, além de bebidas importadas. No caso dos presos, o complemento alimentar poderia vir de um parente ou amigo, ou até mesmo de algum portador que comprasse alimentos na cidade. Neste último caso era preciso estabelecer parcerias com funcionários para burlar as normas. É importante ter em mente a interação da prisão com a sociedade ao tentarmos compreender a comunidade prisional da Bahia oitocentista. Em 1867, por exemplo, foi registrada a presença de quitandeiras no pátio da penitenciária, o que era proibido pelo regulamento (Villasboas, 1868).

Aqueles que dependiam exclusivamente da comida fornecida pela Santa Casa de Misericórdia, os chamados presos pobres, tinham uma dieta incompatível com as necessidades nutricionais básicas. Nota-se, por exemplo, na tabela alimentar a ausência absoluta 
de vegetais e leite, o que poderia resultar na carência de vitamina A e de cálcio. A substituição da carne fresca pela carne-seca gerava outro prejuízo nutricional, pois o processo de salga e a perda de água resultavam também na perda de vitamina B1 (Rios, 2006). A falta de vitamina B1 (tiamina) provocava inúmeras doenças, entre as quais o beribéri, que afeta os sistemas nervoso e cardiovascular. Vale ressaltar que não encontrei caso algum entre os presos. Venétia Rios (2006, p.162) aponta o surto de beribéri no Asilo São João de Deus, em Salvador, nos período de 1877 a 1904. A autora ressalta a dificuldade dos médicos da época em diagnosticar essa doença. No entanto, foram registrados entre os presos casos de anemia, o que denuncia a insuficiência de ferro, pois, mesmo tendo a carne-seca como parte da alimentação, ela poderia estar sendo ingerida em dose insuficiente. A dieta constante na Tabela 2 também explica os vários casos de constipação, gastrite, diarreia e muitas outras, inclusive as doenças de pele (Karasch, 2000).

Outro ponto a ser observado na tabela de alimentação refere-se à fixação das medidas, o que estava em harmonia com o pensamento médico da época. Acreditava-se que a combinação dos alimentos, nas medidas exatas, acompanhada da disciplina alimentar, que consistia em normas de comportamento e cumprimento de horários, contribuía para a reabilitação do interno (Rios, 2006). Jeremy Bentham (1997, p.217) considerou um erro "limitar a quantidade e impor medidas fixas" na alimentação dos presos, "um verdadeiro ato de desumanidade". Suas considerações parecem não ter influenciado os reformadores brasileiros, pois a medida justa do alimento era a tônica nos regulamentos prisionais. De qualquer forma, a Casa de Prisão adaptou a disciplina alimentar de acordo com a sua realidade. Vejamos o que dizia o regulamento.

Art. 45. O almoço das 7 horas para as 8 horas da manhã será servido por empregados do estabelecimento, a cada preso, em uma caneca de folha com colher e garfo de dentes curvos de pau ou chifre. $O$ jantar será às 2 da tarde.

Art. 46. Os presos alimentados à sua custa mandarão vir a comida nas horas marcadas no artigo antecedente. As pessoas que a trouxerem, serão acompanhadas por um guarda até a porta da prisão, onde este examinará a mesma comida, para que com ela não se achem objetos proibidos. Feito isto, serão levadas para o quarto exterior do edifício, onde esperarão que as chamem para tomar as vasilhas que houverem trazido (Regulamento..., 1863, p.10).

Os primeiros talheres de chifre, 150 garfos e colheres, foram fabricados pelos presos em 1862. Naquela ocasião, algumas peças foram encaminhadas ao chefe de polícia, que pareceu satisfeito, informando ao administrador que as amostras recebidas "foram levadas desta Secretaria por pessoas que quiseram apreciar o trabalho dos sentenciados ai recolhidos" (Chefe de polícia..., 21 jun. 1862). As refeições eram distribuídas em marmitas numeradas (Costa, 1861). Para se comunicar com os guardas durante a refeição, o preso deveria tocar uma sineta e, ao ser atendido, falar em voz baixa. Nesse caso, e em outros do regulamento, a imposição de falar em voz baixa fazia parte dos mecanismos de dominação utilizados pelos dirigentes. Aqueles que arcavam com sua própria alimentação estavam desobrigados de seguir o cardápio da Santa Casa. No caso de não receberem a comida de fora, ainda lhes restava uma segunda chance: após o término da refeição, um guarda deveria fazer a inspeção e, no caso de algum preso não ter recebido sua marmita, "embora seja dos que se alimentam 
à sua custa, lhe mandará fornecer a comida necessária" (Regulamento..., 1863, p.10). A vida diária da prisão não correspondia à ordem alimentar expressa no regulamento. Um episódio ocorrido em 1864 é emblemático para entendermos a dificuldade da aplicação dessas normas.

No dia 5 de junho, Marcos Pereira de Sales, vaqueiro, 27 anos, solteiro, sentenciado a seis anos de prisão com trabalho, por homicídio, se encontrava fora de sua cela executando serviços internos quando recebeu a visita de duas mulheres de sua família. Marcos, inicialmente preso no Quartel da Palma, foi removido para a Casa de Prisão em 1863 (Cento e setenta e dois..., s.d.). Acompanhemos o restante da história nas palavras de Carlos Manoel da Silva, que na época exercia a função de ajudante do administrador Lucio Bento Cardozo.

Pediram-me estes [o preso Marcos e suas visitas] a permissão para juntos se proverem de alguma comida de que vinham elas [as visitas] munidas, no que consenti (por ser isso de costume) mediante efetiva assistência, no corredor das oficinas contígua a casa de minha residência dando-lhe formalmente o respectivo cartão de saída; fato este tão bem presenciado por diversos Guardas empregados desta Casa, acontecendo porém, que um destes despeitado por algum, (sic) ou pelo que quer que seja, afastando-se de seus deveres, na qualidade de meu subordinado, passou ao excesso de repreender-me, faltando-me com o respeito que me é devido, e ameaçando-me, de que faria imediatamente ciente ao Sr. Administrador da ocorrência de tão simples fato, o qual no seguinte dia, teve de censurar o meu justo procedimento, asseverando-me de que havia levado ao conhecimento das Autoridades, pelo que vejo-me na indeclinável necessidade, de com toda minuciosidade, e com a verdade que me é própria, levar ao conhecimento de V.Sa. todo ocorrido; a fim de que não seja minha reputação (alias bem conhecida) atrozmente denegrida por um [rasurado] d'esta ordem" (Silva, 1864).

Vemos que os costumes das prisões coloniais eram lembrados também pelos funcionários, pois que Silva infringiu as regras de visita e de alimentação "por ser isso de costume". ${ }^{22}$ Tampouco, naquele momento, era legal o preso executar serviços internos. ${ }^{23}$ Por outro lado, é possível que Marcos tenha corrompido o ajudante Silva para que este facilitasse sua vida de preso. Alguns anos mais tarde, em 1867, Silva teve comportamentos que reforçam essa última hipótese. Ele foi acusado de escrever bilhetes para o comandante da guarda, autorizando a saída de alguns presos e consentindo que estes passassem o dia todo nas ruas da cidade (Processo crime..., fls.5-7, s.d.). Era óbvio que Silva cobrava por esses 'favores'.

Outro ponto que diverge do regulamento é que não eram os guardas que distribuíam a comida, e sim os presos (Administrador..., 19 jul. 1862). Em novembro de 1863, o administrador pediu providências ao chefe de polícia dizendo ser "indispensável a este estabelecimento um pessoal para o serviço da cozinha, distribuição da comida aos presos, e outros misteres; para que não continue semelhante serviço a ser feito pelos próprios presos como se costumava" (Administrador..., 2 nov. 1863). A solução apontada pelo administrador foi utilizar "seis africanos livres que se prestem aos serviços referidos" (Administrador..., 2 nov. 1863). ${ }^{24}$ No entanto, a Santa Casa conseguiu autorização do chefe de polícia para empregar alguns presos neste serviço. Essa opção caracteriza também a exploração da mão de obra dos presos, que certamente receberiam menos do que serventes contratados na cidade. No dia 19 de junho de 1862, o preso José Felipe do Nascimento fazia a distribuição do jantar, 
quando a presa Jesuína Maria do Bomfim lhe atirou um caneco com água e, em seguida, passou a fazer-lhe ofensas verbais, provavelmente reagindo a alguma provocação de José Felipe. Jesuína cumpria pena por crime de roubo e esteve presa na cadeia do Aljube antes de ser transferida para a penitenciária, em 1861. Não localizei outras informações sobre José Felipe. Naquele mesmo dia, dois companheiros de cela, José Andrade Freire e José Porfírio dos Santos, se agrediram fisicamente, saindo "ambos arranhados". Passados três dias, José Porfírio saiu da solitária e ficaram presos José Porfírio e Jesuína, "por se conservarem em uma altivez extraordinária" (Administrador..., 10 jun. 1862, 22 jun. 1862). Essa observação revela que os presos não se rendiam facilmente às normas disciplinares. José e Jesuína, mesmo na solitária, deram sinais de resistência e autoestima.

A frequência dos castigos nas solitárias não surtia o efeito esperado pelos dirigentes, ou seja, não disciplinava o preso nos moldes desejados pela instituição. A violência entre os presos também reflete o que essas pessoas viviam do lado fora, pois a prisão geralmente reproduz os valores e práticas da sociedade a que ela pertence. As presas Victoria e Ignácia, condenadas por crime de morte, também brigaram e foram punidas da mesma forma (Administrador..., 18 jun. 1862), assim como os presos Clemente Manuel Ferreira e Mathias dos Santos, ambos condenados por crime de morte. Um caso mais grave ocorreu em outubro de 1865. O preso Manoel de Jesus Neves feriu com uma faca o peito do companheiro Theodoro Jacintho Maciel, que foi internado no Hospital da Caridade. Ambos cumpriam pena por crime de morte. O chefe de polícia ordenou que Manoel fosse mantido na solitária até "segunda ordem", ignorando os prazos de permanência previstos no regulamento (Chefe de polícia..., 4 out. 1865). Vejamos o que dizia o regulamento sobre os graus e as formas de punição.

Art. 29. As penas disciplinares, que podem ser impostas aos presos para correção de faltas no cumprimento das disposições deste regulamento, depois de admoestados e repreendidos pelo administrador, são as seguintes: $1^{\text {a }}$ Retenção em célula solitária por um a cinco dias; $2^{a}$ Restrição das concessões dos art. 14 e 18 [passeios no corredor e visitas] por um a três dias; $3^{\mathrm{a}}$ Detenção em célula solitária obscura por um a três dias; $4^{\mathrm{a}}$ Prisão em ferros por um a cinco dias; $5^{\mathrm{a}}$ Restrição alimentar até quinze dias ou um mês (Regulamento..., 1863, p.7-9).

Quebrar o silêncio ou violar 'preceitos' era motivo de advertência, caso o preso a ignorasse seria enquadrado na primeira pena, e em caso de reincidência, na segunda. Ofensa verbal entre presos ou envolvendo funcionários enquadraria o preso na segunda pena. Em caso de ameaça a outro preso, a pena aplicada seria a terceira; se precedida de violência, o tempo de permanência era dobrado. Na hipótese de a violência gerar ferimento grave, a culpa era agravada, e o preso enquadrado na quarta ou quinta pena. Nestes dois últimos casos, quem decidia era o chefe de polícia. Todas as outras penas poderiam ser aplicadas pelo administrador. Em qualquer dessas faltas, se cometidas contra funcionários, a punição seria cumprida em dobro (Regulamento..., 1863, p.7-9). Esse sistema de punição rompia com a era das torturas físicas, agora substituídas pelo martírio moral e alimentar do preso, o que caracterizava a prisão moderna. Jeremy Bentham, o criador do panóptico, defendeu os castigos como um método corretivo para as "ofensas cometidas na própria Prisão". Para ele, o confinamento na solitária tinha a vantagem de não oferecer danos à saúde, como 
acontecia com os castigos corporais. Porém "deve-se dar ao diretor só o poder de condenar os prisioneiros à solidão: os demais castigos devem ser administrados na presença e sob a autoridade de alguns magistrados" (Bentham, 1997, p.222). Na Casa de Prisão da Bahia era o administrador quem aplicava a maioria dos castigos. Para Foucault, o isolamento dos presos "garante que se possa exercer sobre eles, com o máximo de intensidade, um poder que não será abalado por nenhuma outra influência; solidão é a condição primeira da submissão total" (Foucault, 1997, p.212). Com vimos, não foi o que ocorreu na penitenciária baiana, onde o uso constante da solidão como castigo não abalou a autonomia dos presos.

\section{Considerações finais}

Com a inauguração da Casa de Prisão com Trabalho, a província baiana pode ter caminhado alguns passos rumo à 'civilização'. No entanto, a realidade do aprisionamento colonial ainda estava presente no cotidiano das cadeias da cidade e, em parte, na nova instituição. Na Cadeia da Correção, por exemplo, uma cadeia comum de Salvador, sem nenhum projeto de reabilitação, os presos foram mantidos até o final do século XIX em celas lotadas e sem a devida separação de acordo com a natureza do crime cometido, como mandava a lei desde a Constituição de 1824. Na penitenciária os presos eram distribuídos em número de dois por cela; portanto, não havia o problema da superlotação. Aparentemente a nova instituição apresentava melhorias se comparada com as antigas cadeias, pelo menos no que diz respeito às acomodações. Não quero dizer com isso que os presos pensassem dessa forma. Sem as oficinas de trabalho e com as obras incompletas, eles foram privados dos passeios e das visitas, permanecendo trancados dia e noite nas celas. Essa situação inicial gerou inúmeras reivindicações. ${ }^{25} \mathrm{~A}$ continuidade das práticas antigas de encarceramento foi estimulada também pelo Código Criminal que herdou as penas de galés, morte e deportação do Livro 5 das Ordenações Filipinas. As penas do novo código variavam de acordo com a condição jurídica do criminoso, o que ia de encontro às doutrinas penitenciárias, fundamentadas em princípios igualitários de punição. Para Aufderheide (1976, p.332, tradução livre), as "punições diferenciadas para escravos e livres significavam somente uma implementação parcial das reformas projetadas".

Durante os quase trinta anos de construção da penitenciária baiana, as autoridades não conseguiram chegar a um consenso, fosse em relação ao prédio ou às correlatas doutrinas penitenciárias. A indecisão sobre qual o sistema penitenciário a ser adotado Auburn ou Pensilvânia - comprometeu a construção do edifício, que ficou reduzido a dois raios e, ainda assim, com sérios problemas na sua arquitetura, pois o projeto arquitetônico deveria estar em harmonia com um ou outro sistema, uma vez que cada um exigia estruturas físicas diferentes. A instituição não seguiu na íntegra nenhum desses modelos. Diria que, no máximo, o sistema de Auburn foi adaptado à realidade prisional da Bahia, para não negar totalmente a influência do modelo estrangeiro.

Vimos que as condições de saúde e de alimentação dos presos da penitenciária, no período estudado, enfrentavam problemas já existentes antes da reforma prisional. Em 1858, por exemplo, a Santa Casa de Misericórdia também fornecia a alimentação nas 
cadeias públicas da cidade. A má qualidade desses alimentos é tema constante em cartas de presos e do próprio governo à provedoria da Santa Casa (Requerimento..., s.d.). ${ }^{26}$ Observamos também que os presos não se renderam à tentativa de dominação, nem mesmo diante da necessidade do tratamento médico e da alimentação. É importante ressaltar que eles foram sujeitos ativos dessa história. Muitas vezes, a dificuldade das autoridades em 'modernizar' os regulamentos das prisões refletia também a resistência dos presos em não abrir mão de velhos costumes prisionais. Podemos nos inspirar em E.P. Thompson para pensar a relação entre a rigidez das doutrinas penitenciárias e o afrouxamento das normas prisionais. Segundo o autor, os costumes podiam levar as pessoas a entrar em conflito com a lei, que, para atuar como mediadora das relações de classes, precisa ter sua lógica própria (Thompson, 1987). O regulamento da prisão também precisava ter sua lógica; caso contrário, não funcionaria, dado que as concessões resultavam do conflito entre os presos e o sistema penitenciário. Sendo assim, as brechas no regulamento e as concessões dos dirigentes devem ser interpretadas como resultado de pressão e negociação, o que visava garantir um mínimo de tranquilidade no seio da comunidade prisional.

\section{NOTAS}

* Este texto é parte de uma pesquisa mais ampla desenvolvida durante o mestrado no Programa de Pósgraduação em História da UFBA, sob a orientação do professor doutor João José Reis, a quem agradeço as sugestões e indicação de fontes e bibliografia. Agradeço aos professores Pedro Moraes Trindade e Venétia Durando Braga Rios os comentários desde a primeira versão. Sou igualmente grata ao editor científico da revista História, Ciências, Saúde - Manguinhos, professor doutor Jaime L. Benchimol, cujas sugestões permitiram melhorar sensivelmente este texto. A pesquisa contou com o apoio do CNPq.

${ }^{1}$ Sobre a Bahia, ver Trindade, 2008, p.157-198; para Pernambuco, Albuquerque Neto, 2008; para o Rio de Janeiro, Araújo, 2009, e Pessoa, 2000; para São Paulo, Salla, 1999; e para Porto Alegre, ver Paiva, 2002.

${ }^{2}$ Sobre o panóptico ver Bentham, 1997, p.199-229; Silva, 2000; Foucault, 1987.

${ }^{3}$ A diferença era que no sistema de Auburn as atividades dos presos eram realizadas de maneira coletiva no mais absoluto silêncio, e à noite os presos eram isolados em celas. No modelo da Pensilvânia ou Filadélfia, todas as atividades eram realizadas na mais completa solidão, em celas especialmente planejadas, para que os presos pudessem trabalhar e dormir no mesmo local. Para uma discussão detalhada sobre esses sistemas penitenciários ver Foucault, 1987. Sobre os debates dos reformadores baianos frente a esses sistemas, ver Trindade, 2008, p.157-198.

${ }^{4}$ Sobre a implantação dessas instituições, ver Fraga Filho, 1999; Silva, 2005; Rios, 2006; Matta, 1996; Leal, 1996; Reis, 1991.

${ }^{5} \mathrm{Na}$ Casa de Correção da Corte era constante a reclamação dos seus diretores quanto à manutenção do calabouço na instituição. Eles alegavam a incompatibilidade dos castigos, aplicados aos escravos, com os objetivos da penitenciária. Sobre o assunto ver Pessoa, 2000, p.123.

${ }^{6}$ As cadeias de Salvador no século XIX eram a da Relação (1640-1845), localizada no subsolo da Câmara Municipal de Salvador; cadeia do Aljube (1833-1861), localizada na antiga ladeira do Aljube, nas imediações de onde hoje está o viaduto da Sé, esquina com a ladeira da Praça; a Casa ou Cadeia da Correção (1832-séc. XX), localizada no forte de Santo Antônio Além do Carmo; e a cadeia do Barbalho (1845-1864), localizada no forte do Barbalho. Por curiosidade, vale destacar que as inúmeras fortalezas na cidade também tinham a função de prisão militar, geralmente destinadas a militares e presos políticos. Contudo, algumas delas recebiam presos civis como, por exemplo, 'a prisão dos galés', localizada no Arsenal de Marinha, e a prisão da fortaleza do Mar. Nas primeiras décadas do século XIX, existiam também os navios-prisões, incluindo o Presiganga. Um estudo detalhado sobre o aparelho prisional de Salvador no Oitocentos está em Trindade, 2008, p.157-198.

${ }^{7}$ A grafia dos documentos transcritos no decorrer deste texto foi atualizada, com exceção da correspondência escrita pelos presos. Nesta mantive a grafia e a pontuação originais de maneira a sugerir ao 
leitor o grau de letramento dos seus autores. Doravante a Casa de Prisão com Trabalho poderá também ser indicada como penitenciária ou Casa de Prisão.

${ }^{8}$ O Hospital da Caridade era administrado pela Santa Casa de Misericórdia da Bahia. Sobre sua história e cotidiano no século XIX, ver Rios, 2001.

${ }^{9}$ A área da Casa de Prisão com Trabalho era vizinha às terras do Engenho de Conceição. Daí o local ser popularmente chamado de Engenho da Conceição. Um velha cantiga de capoeira datada da Primeira República e até hoje cantada nas rodas de capoeira se refere à penitenciária da Bahia como Engenho da Conceição. A própria documentação de época muitas vezes traz no cabeçalho Cadeia da Conceição mesmo depois da instituição ter sido novamente elevada à categoria de Casa de Prisão com Trabalho ou penitenciária. Em 1908, em sua tese de doutoramento, o médico higienista Octávio Torres também se refere à penitenciária da Bahia como Engenho da Conceição. Sobre isso ver Torres, 1908, p.39.

${ }^{10}$ Um estudo detalhado sobre esses 111 presos está em Trindade, 2011.

${ }^{11}$ Sobre a reforma prisional e a legislação brasileira, ver Trindade, 2008, p.176-181. Uma discussão mais aprofundada sobre as penas e os delitos no Código Criminal do Império, relacionados com a reforma prisional, pode ser vista em Albuquerque Neto, 2008, p.27-51.

${ }^{12}$ Sobre o assunto, ver, por exemplo, a mesa-redonda de 20 de maio de 1978, de que participaram Michel Foucault, Catherine Duprat, Jacques Leonard, Michellle Perrot, Jacques Revel, Carlo Ginzburg, entre outros. Uma das questões debatidas e apresentadas a Foucault foi a subsistência, na França, no decorrer no século XIX, de outros modos de punir, como pena de morte, deportação etc. (Perrot, 1980, p.40). Para os Estados Unidos ver, entre outros, Rothman, 1998, p.100-116.

${ }^{13}$ Sobre correspondências de presos ver Aguirre, 2001, p.342-367. Para a Bahia ver Trindade, 2009, p.377-420.

${ }^{14}$ A comissão inspetora era composta por Manoel Messias de Leão, João Ladislau Japiassú de Figueiredo Mello, José de Barros Reis, Demetrio Cyriaco Tourinho e José Lopes Pereira de Carvalho. Vemos nesse grupo médicos, engenheiros e bacharéis, as profissões que costumavam se apropriar das questões públicas no século XIX (Chaves, 1862, p.6-7). Sobre as profissões imperiais, ver Coelho, 1999, p.65. Sobre a disputa dos médicos com o poder público nos assuntos da saúde pública, ver Chalhoub, 1996; sobre a Bahia, ver Rios, 2001.

15 Desse mapa consta o total de 168 presos, estando no hospital 11 homens e uma das 14 mulheres. No outro mapa, datado de 12 de dezembro de 1863, o total era de 179 presos, estando no hospital vinte homens e três das 15 mulheres.

${ }^{16} \mathrm{O}$ total de presos em outubro de 1865 era de 176 . O movimento de internamento e alta dos presos, referente ao ano de 1865, foi levantado por mim a partir dos ofícios do chefe de polícia e da irmã superiora do Hospital da Caridade (Diversas autorizações..., s.d.).

17 Diversos ofícios de alta expedidos pela irmã superiora para o administrador da Casa de Prisão com Trabalho, 15 fev. 1865, 15 abr. 1865, 9 jul. 1865, 9 ago. 1865, 7 set. 1865, 12 set. 1865, 13 ago 1865, Seção Colonial e Provincial, Fundo Polícia; maço 5926 (Arquivo Público do Estado da Bahia/APEBa). Diversas autorizações de internamentos expedidas pelo chefe de polícia e endereçadas para o administrador da Casa de Prisão com Trabalho, 28 mar. 1865, 22 abr. 1865, 27 maio 1865, 21 ago. 1865, 23 out. 1865, Seção Colonial e Provincial, Fundo Polícia; maço 5926, (APEBa).

${ }^{18} \mathrm{O}$ agrupamento das doenças da Tabela 1 foi inspirado no método utilizado por Mary Karasch (2000) para estudar as doenças dos escravos no Rio de Janeiro do século XIX.

${ }^{19} \mathrm{O}$ preso poderia solicitar o seu internamento por meio de uma petição endereçada ao médico. Este encaminhava o pedido com o seu parecer ao chefe de policia, que autorizava ou não a transferência do doente. Ao receber alta do hospital, a irmã superiora emitia um ofício ao administrador da Casa de Prisão com Trabalho, que providenciava uma escolta para acompanhar o retorno do preso. As irmãs de caridade pertenciam à Congregação São Vicente de Paula e ocupavam cargos administrativos nas enfermarias do hospital. Sobre as irmãs, ver Rios, 2001, p.143-144.

${ }^{20}$ Esse decreto imperial serviu como regulamento da Casa de Correção do Rio de Janeiro. Também foi seguido, com algumas adaptações, pela Casa de Correção de São Paulo. A Bahia o utilizou parcialmente até implantar o seu próprio regulamento em outubro de 1863.

${ }^{21}$ O horário das refeições pode parecer incomum se comparado aos costumes de hoje. No entanto, "entre os meados do século XIX e até as primeiras décadas do XX, a cidade conheceu outra divisão do tempo alimentar. O almoço era servido em torno das 10 horas; o jantar por volta das 18 horas, e a ceia próximo às 20 horas" , conforme Rios, 2006, p.163. 
22 O primeiro carcereiro da Casa de Prisão com Trabalho exercia antes essa função na Cadeia da Correção, sendo comum o chefe de polícia remanejar os funcionários das prisões. Daí a possibilidade de Silva já ter trabalhado em alguma cadeia da província e ter levado suas experiências para a penitenciária (Chefe de polícia..., 31 out. 1865).

${ }^{23}$ Segundo a legislação, os presos deveriam trabalhar em oficinas sob normas disciplinares. As oficinas só foram inauguradas em 1865, entretanto, os costumes também prevaleceram, uma vez que, ao entrarem em funcionamento, o chefe de polícia também autorizou que os presos desempenhassem serviços internos e remunerados. Mas o caso do preso Marcos demonstrou que a prática costumeira do trabalho interno antecedeu a sua legalização pelo chefe de polícia, como já era de esperar.

${ }^{24} \mathrm{O}$ termo 'africano livre' denominava a condição jurídica daqueles africanos que eram apreendidos após a proibição do tráfico pela lei de 1831. Essa lei imperial também determinava que os africanos apreendidos no contrabando deveriam ser mandados de volta à África, o que normalmente não acontecia. Esses africanos ficavam sob a tutela do governo brasileiro, que os obrigava a trabalhar nas obras públicas. Sobre o assunto, ver Florence, 2002.

${ }^{25}$ Ver Neves, 1862, entre outras.

${ }^{26}$ Em 1833, o "contrato de sustento dos presos" entre a Santa Casa de Misericórdia e o governo da província custava aos cofres públicos "doze contos de reis anuais" (Requerimento..., s.d.). Em 1858, os presos das cadeias do Barbalho e da Correção reclamaram ao chefe de polícia da péssima qualidade da comida da Santa Casa (Mordomo..., 8 jun. 1858).

\section{REFERÊNCIAS}

ADMINISTRADOR...

Administrador da Cadeia do Engenho da Conceição para o chefe de polícia. Salvador. Seção Colonial e Provincial, Fundo Polícia, maço 6272 (Arquivo Público do Estado da Bahia). 2 nov. 1863.

\section{ADMINISTRADOR...}

Administrador da Casa de Prisão com Trabalho para o chefe de polícia. Salvador. Seção Colonial e Provincial, Fundo Polícia, maço 6272 (Arquivo Público do Estado da Bahia). 19 jul. 1862.

\section{ADMINISTRADOR...}

Administrador para o chefe de polícia.

Salvador. Seção Colonial e Provincial, Fundo

Polícia, maço 6272 (Arquivo Público do Estado da Bahia). 22 jun. 1862.

\section{ADMINISTRADOR...}

Administrador para o chefe de polícia. Salvador. Seção Colonial e Provincial, Fundo Polícia, maço 6272 (Arquivo Público do Estado da Bahia). 18 jun. 1862

\section{ADMINISTRADOR...}

Administrador para o chefe de polícia.

Salvador. Seção Colonial e Provincial, Fundo Polícia, maço 6272 (Arquivo Público do Estado da Bahia). 10 jun. 1862.

\section{AGUIRRE Carlos.}

Disputed views of incarceration in Lima, 18901930: the prisoners' agenda for prison reform. In: Salvatore, Ricardo; Aguirre, Carlos; Joseph, Gilbert M. (Org.). Crime and punishment in Latin
America: law and society since late colonial times. London: Duke University. p.342-367. 2001.

ALBUQUeRQUe, Antonio Coelho de Sá e. Fala que recitou na abertura da Assembleia Legislativa da Bahia o presidente da província, conselheiro Antonio Coelho de Sá e Albuquerque, no dia $1^{o}$ de março de 1863. Salvador: Typographia Poggetti. 1863.

ALBUQUERQUE NETO, Flávio de Sá Cavalcanti de.

A reforma prisional no Recife oitocentista: da Cadeia à Casa de Detenção (1830-1874). Dissertação (Mestrado) - Centro de Filosofia e Ciências Humanas, Universidade Federal de Pernambuco, Recife. 2008.

ARAÚJO, Carlos Eduardo Moreira de. Cárceres imperiais: a Casa de Correção do Rio de Janeiro - seus detentos e o sistema prisional do Império (1830-1861). Tese (Doutorado) - Instituto de Filosofia e Ciências Humanas, Universidade Estadual de Campinas, Campinas, 2009.

ATA...

Ata da comissão inspetora. Salvador. Seção Colonial e Provincial, Fundo Polícia, maço 5942 (Arquivo Público do Estado da Bahia). 5 dez. 1861.

AUFDERHEIDE, Patrícia.

Order and violence: social deviance and social control in Brazil (1780-1840). Tese (Doutorado) - University of Minnesota, Minnesota, 1976. 
BARRETO, Maria Renilda Nery; ARAS, Lina Maria Brandão de.

Salvador, cidade do mundo: da Alemanha para a Bahia. História, Ciências, SaúdeManguinhos, Rio de Janeiro, v.10, n.1, p.151-172. 2003.

BENTHAM, Jeremy.

Panóptico: memorial sobre um novo princípio para construir casas de inspeção e, principalmente, prisões. Revista de História, Rio de Janeiro, v.7, n.14, p.199-229. 1997.

BRASIL.

Decreto no 678, artigos 66 e 37.6 jul. 1850.

CARCEREIRO...

Carcereiro da Casa de Correção para o administrador da Casa de Prisão com Trabalho. Salvador. Seção Colonial e Provincial, Fundo Polícia, maço 5942 (Arquivo Público do Estado da Bahia). 28 abr. 1865.

CARVALHO, José Eduardo Freire de. Médico José Eduardo Freire de Carvalho para o chefe de polícia. Salvador. Seção Colonial e Provincial, Fundo Polícia, maço 6286 (Arquivo Público do Estado da Bahia). 25 ago. 1862.

CENTO E SETENTA E DOIS...

Cento e setenta e dois presos que se achão actualmente recolhidos nesta Casa. Salvador. Seção Colonial e Provincial, Fundo Polícia, maço 6287 (Arquivo Público do Estado da Bahia). s.d.

CHALHOUB, Sidney.

Cidade febril: cortiços e epidemias na Corte imperial. São Paulo: Companhia das Letras. 1996.

CHALHOUB, Sidney.

Visões da liberdade: uma história das últimas décadas da escravidão na Corte. São Paulo: Companhia das Letras. 1990.

CHAVES, José Augusto.

Relatório apresentado ao excelentíssimo senhor conselheiro Joaquim Antão Fernandes Leão, presidente da província da Bahia, pelo $4^{o}$ vicepresidente o excelentíssimo senhor doutor José Augusto Chaves, no ato de passar-lhe a administração da província. Salvador: Typographia de Antonio Olavo de França Guerra. 1862.

CHEFE DE POLÍCIA...

Chefe de polícia para o administrador da Casa de Prisão com Trabalho. Salvador. Seção Colonial e Provincial, Fundo Polícia, maço 5926 (Arquivo Público do Estado da Bahia). 8 nov. 1865

CHEFE DE POLÍCIA...

Chefe de polícia para o carcereiro da cadeia da correção. Salvador. Seção Colonial e Provincial, Fundo Polícia, v. 5745, fl. 244v -245 (Arquivo Público do Estado da Bahia). 31 out. 1865.

CHEFE DE POLÍCIA...

Chefe de polícia para o administrador da Casa de Prisão com Trabalho. Salvador. Seção Colonial e Provincial, Fundo Polícia, maço 5926 (Arquivo Público do Estado da Bahia). 25 out. 1865.

\section{CHEFE DE POLÍCIA...}

Chefe de Polícia para o administrador da Casa de Prisão com Trabalho. Salvador. Seção Colonial e Provincial, Fundo Polícia, maço 5926 (Arquivo Público do Estado da Bahia). 4 out. 1865.

CHEFE DE POLÍCIA...

Chefe de polícia para o administrador da Casa de Prisão com Trabalho. Salvador. Seção Colonial e Provincial, Fundo Polícia, maço 5926 (Arquivo Público do Estado da Bahia). 5 set. 1865.

CHEFE DE POLÍCIA...

Chefe de polícia para o administrador da Casa de Prisão com Trabalho. Salvador. Seção Colonial e Provincial, Fundo Polícia, maço 5926 (Arquivo Público do Estado da Bahia). 16 ago. 1865.

\section{CHEFE DE POLÍCIA...}

Chefe de polícia para o administrador da Casa de Prisão com Trabalho. Salvador. Seção Colonial e Provincial, Fundo polícia, maço 5925 (Arquivo Público do Estado da Bahia). 21 jun. 1862.

CHEFE DE POLÍCIA...

Chefe de polícia para o presidente da província. Salvador. Seção Colonial e Provincial, Fundo Presidência da Província, maço 3139-25 (Arquivo Público do Estado da Bahia). 12 dez. 1861.

COELHO, Edmundo Campos.

As profissões imperiais: medicina, engenharia e advocacia no Rio de Janeiro (1822-1930). Rio de Janeiro: Record. 1999.

COSTA, Antonio Pedro da.

Administrador Antonio Pedro da Costa para o Chefe de polícia. Salvador. Seção Colonial e Provincial, Fundo Presidência da Província, maço 3139-25. (Arquivo Público do Estado da Bahia). 11 dez. 1861.

\section{CUNHA, Pereira da.}

Chefe de polícia Pereira da Cunha para o carcereiro da cadeia da correção José Bernardo da Cunha. Salvador. Seção Colonial e Provincial, Fundo Polícia, maço 5745, fls. 244v.-245 (Arquivo Público do Estado da Bahia). 31 out. 1861. 
DIVERSAS AUTORIZAÇÕES...

Diversas autorizações de internamentos expedidas pelo chefe de polícia e endereçadas para o administrador da Casa de Prisão com Trabalho. Salvador. Seção Colonial e Provincial, Fundo Polícia, maço 5926 (Arquivo Público do Estado da Bahia). 28 mar. 1865, 22 abr. 1865, 27 maio 1865, 21 ago. 1865, 23 out. 1865.

DIVERSAS AUTORIZAÇÕES...

Diversas autorizações de remoção de presos da Casa de Prisão com Trabalho para o hospital, assinadas pelo chefe de polícia e do hospital para a Casa de Prisão com Trabalho, assinadas pela irmã superiora do Hospital da Caridade. Salvador. Seção Colonial e Provincial, Fundo Polícia, maço 5926 (Arquivo Público do Estado da Bahia). s.d.

DIVERSAS GUIAS...

Diversas guias de transferências de presos para o hospital e para a Casa de Prisão com Trabalho. Salvador. Seção Colonial e Provincial, Fundo Polícia, maço 5926 (Arquivo Público do Estado da Bahia). s.d.

DIVERSOS OFÍCIOS...

Diversos ofícios de alta expedidos pela irmã superiora para o administrador da Casa de Prisão com Trabalho. Salvador. Seção Colonial e Provincial, Fundo Polícia; maço 5926 (Arquivo Público do Estado da Bahia). 15 fev. 1865, 15 abr. 1865, 9 jul. 1865, 9 ago. 1865, 13 ago. 1865,7 set. 1865,12 set. 1865 .

\section{DIVERSOS OFÍCIOS...}

Diversos ofícios do chefe de polícia e do Hospital da Caridade. Salvador. Seção Colonial e Provincial, Fundo Polícia, maço 5926 (Arquivo Público do Estado da Bahia). s.d.-a

DIVERSOS OFÍCIOS...

Diversos ofícios do chefe de polícia para o administrador, autorizando o internamento, e da irmã superiora para o administrador da CPCT informando a alta do preso. Seção Colonial e Provincial, Fundo Polícia, maço 5926 (Arquivo Público do Estado da Bahia). s.d.-b

FLORENCE, Afonso Bandeira.

Entre o cativeiro e a emancipação: a liberdade dos africanos livres no Brasil (1818-1854).

Dissertação (Mestrado) - Faculdade de

Filosofia e Ciências Humanas, Universidade Federal da Bahia, Salvador. 2002.

FOUCAULT, Michel.

Vigiar e punir: história da violência nas prisões. Petrópolis: Vozes. 1987.

FRAGA FILHO, Walter.

Mendigos, moleques e vadios na Bahia do século XIX. Salvador: EdUFBA. 1999.
HENRIQUES, João de Araujo Freitas. Chefe de polícia João Antonio de Araujo Freitas Henriques para o administrador da Casa de Prisão com Trabalho. Salvador. Seção Colonial e Provincial, Fundo Polícia, maço 5925 (Arquivo Público do Estado da Bahia). 24 abr. 1862.

IRMÃ SUPERIORA...

Irmã superiora para o administrador da Casa de Prisão com Trabalho. Salvador. Seção Colonial e Provincial, Fundo Polícia, maço 5926 (Arquivo Público do Estado da Bahia). 1 out. 1865.

IRMÃ SUPERIORA...

Irmã superiora para o administrador da Casa de Prisão com Trabalho. Salvador. Seção Colonial Provincial, Fundo Polícia, maço 5926 (Arquivo Público do Estado da Bahia). 13 mar. 1865.

JUNQUEIRA, João José de Oliveira. João José de Oliveira Junqueira, chefe de polícia, para o administrador da Casa de Prisão com Trabalho. Salvador. Seção Colonial e Provincial, Fundo Polícia, maço 5926 (Arquivo Público do Estado da Bahia). 4 nov. 1865.

KARASCH, Mary C.

A vida dos escravos no Rio de Janeiro, 1808-1850. São Paulo: Companhia das Letras. 2000.

LEAL, Maria das Graças Andrade.

$A$ arte de ter um ofício: o Liceu das Artes e Ofícios da Bahia (1872-1977). Dissertação (Mestrado) - Programa de Pós-graduação em História, Universidade Federal da Bahia, Salvador. 1996.

LEITE, Manoel José de Figueiredo. Relatório do provedor da Santa Casa de Misericórdia da Capital da Bahia, Manoel José de Figueiredo Leite, apresentado à mesa da irmandade em sessão de março de 1863. In: Rios, Venétia Durando Braga. Entre a vida e a morte: médicos, medicina e medicalização na cidade do Salvador (1860-1880). Dissertação (Mestrado) - Faculdade de Filosofia e Ciências Humanas, Universidade Federal da Bahia, Salvador. p.124. 2001.

\section{MAPA NUMÉRICO...}

Mapa numérico dos presos existentes na Cadeia da Conceição com declaração de penas a que estão condenados datado de 11 de outubro de 1862. Salvador. Seção Colonial e Provincial, Fundo Polícia, maço 6286 (Arquivo Público do Estado da Bahia). 11 out. 1862.

MATTA, Alfredo Eurico Rodrigues. Casa Pia Colégio de Órfãos de São Joaquim: de recolhido a assalariado. Dissertação (Mestrado) - Programa de Pós-graduação em História, Universidade Federal da Bahia, Salvador. 1996. 
MATTOSO, Kátia M. de Queirós. Bahia: a cidade do Salvador e seu mercado no século XIX. São Paulo: Hucitec. 1978.

\section{MORDOMO...}

Mordomo para o chefe de polícia Polycarpio Lopes de Leão. Salvador. Livro de Registros no 9, A-93 F. 210-211 (Arquivo da Santa Casa de Misericórdia da Bahia).

8 jun. 1858.

NASCIMENTO, Ana Amélia Vieira

Dez freguesias da cidade de Salvador. Salvador: Fundação Cultural do Estado da Bahia. 1986.

NEVES, João Byspo.

João Byspo das Neves para o presidente da província. Salvador. Seção Colonial e Provincial, Fundo Polícia; maço 3082 (Arquivo Público do Estado da Bahia). mar. 1862.

OFICINA SANITÁRIA PANAMERICANA. Boletín de la oficina sanitaria panamericana, Washington, v.9, n.7, p.894. Disponível em: http://bases.bireme.br/. Acesso em: 21 abr. 2011. 1930.

PAIVA, Helena Marisa Vianna.

A Casa de Correção de Porto Alegre, 1889-1898. Dissertação (Mestrado) - Faculdade de História, Pontifícia Universidade Católica do Rio Grande do Sul, Porto Alegre. 2002.

PERROT, Michelle (Org.).

L'impossible prison: recherches sur le système pénitentiaire au XIXème siècle. Paris: Éditions du Seuil. 1980.

PESSOA, Gláucia Tomaz de Aquino. Trabalho e resistência na penitenciária da Corte, 1850-1876. Dissertação (Mestrado) Departamento de História, Universidade Federal Fluminense, Niterói. 2000.

\section{PROCESSO CRIME...}

Processo crime do tenente Manoel Diniz Villasboas. Salvador. Seção Judiciária, Processos Crimes, 20/708/11 (Arquivo Público do Estado da Bahia). s.d.

\section{REGULAMENTO...}

Regulamento da Casa de Prisão com Trabalho da Bahia aprovado pelo presidente da província o conselheiro Antonio Coelho de Sá e Albuquerque em 14 de outubro de 1863. Salvador: Typographia Poggetti. 1863.

RELAÇÃO DE PRESOS...

Relação de presos da Casa de Correção.

Salvador. Seção Colonial e Provincial, Fundo Polícia, maço 6271 (Arquivo Público do Estado da Bahia). s.d.

REQUERIMENTO...

Requerimento para o governo da província cobrando pagamento referente ao contrato de sustento dos presos. Salvador. Livro de Registros no 09/ A-93 fl. 30 (Arquivo da Santa Casa de Misericórdia da Bahia). s.d.

REIS, João José.

A morte é uma festa: ritos fúnebres e revolta popular no Brasil do século XIX. São Paulo: Companhia das Letras. 1991.

RIOS, Venétia Durando Braga.

O asylo de São João de Deus: as faces da loucura. Tese (Doutorado) - Programa de Estudos Pósgraduados em História, Pontifícia Universidade Católica de São Paulo, São Paulo. 2006.

RIOS, Venétia Durando Braga.

Entre a vida e a morte: médicos, medicina e medicalização na cidade do Salvador, 18601880. Dissertação (Mestrado) - Faculdade de Filosofia e Ciências Humanas, Universidade Federal da Bahia, Salvador. 2001.

ROTHMAN, David J. Perfecting the prison: United States, 1789-1865. In: Morris, Norval; Rothman, David J. (Org.). The Oxford history of the prison: the practice of punishment in Western society. New York: Oxford University Press. p.100-116. 1998.

SALLA, Fernando. As prisões de São Paulo, 1822-1940. São Paulo: Annablume. 1999.

SANTOS, Possivanio Vieira dos. Médico interno do Hospital da Caridade, Possivanio Vieira dos Santos, para ao provedor da Santa Casa de Misericórdia da Bahia.

Salvador. Correspondência avulsa do Hospital da Caridade, 1860 (Arquivo da Santa Casa de Misericórdia da Bahia). 4 nov. 1860.

SEIXAS, Eustaquio Primo de.

Considerações sobre o sistema penitenciário adotado pelo Código Penal vigente: tese apresentada ao concurso para preenchimento de uma vaga aberta no Tribunal de Appelação e Revista do Estado da Bahia em 25 de outubro de 1897. Salvador: Typographia e Encadernação do Diário da Bahia. 1897.

SILVA, Carlos Manoel da.

Administrador Carlos Manoel da Silva para o chefe de polícia. Salvador. Seção Colonial e Provincial, Fundo Polícia, maço 6274 (Arquivo Público do Estado da Bahia). 12 fev. 1868.

SILVA, Carlos Manuel da.

Ajudante Carlos Manuel da Silva para o chefe de polícia. Salvador. Seção Colonial e Provincial, Fundo Polícia, maço 6273 (Arquivo Público do Estado da Bahia). 11 jun. 1864.

SILVA, Querino Dias da Querino Dias da Silva para o chefe de polícia. 
Salvador. Seção Colonial e Provincial, Fundo Polícia, maço 6287 (Arquivo Público do Estado da Bahia). 30 out. 1865.

SILVA, Tomaz Tadeu da (Org. e trad.).

Jeremy Bentham: o panóptico. Belo Horizonte: Autêntica. 2000.

SILVA, Vera Nathália dos Santos. Equilíbrio distante: a mulher, a medicina mental e o asilo - Bahia (1874-1912). Dissertação (Mestrado) - Programa de Pós-graduação em História, Universidade Federal da Bahia, 2005.

TABELA...

Tabela para o fornecimento de alimentação de presos pobres da casa de prisão com trabalho e cadeia da correção. Salvador. Seção Colonial e Provincial, Fundo Polícia, maço 6274 (Arquivo Público do Estado da Bahia). 1869.

THOMPSON, Edward P.

Senhores e caçadores. Rio de Janeiro: Paz e Terra. 1987.

TORRES, Octavio.

A cidade do Salvador perante a higiene. Salvador: Typographia Moderna. 1908.
TRINDADE, Cláudia Moraes.

O nascimento de uma penitenciária: os primeiros presos da Casa de Prisão com Trabalho da Bahia, 1861-1865. Tempo, Niterói, v.16, n.30, p.167-196. 2011.

TRINDADE, Cláudia Moraes.

Para além da ordem: o cotidiano prisional da Bahia oitocentista a partir da correspondência de presos. História, São Paulo, v.28, n.2, p.377420. 2009.

TRINDADE, Cláudia Moraes.

A reforma prisional na Bahia oitocentista. Revista de História, São Paulo, n.158, p.157-198. jun. 2008.

VILLASBOAS, Manuel Diniz.

Resposta apresentada pelo ex-administrador da Casa de Prisão com Trabalho da província da Bahia, tenente-coronel Manoel Diniz Villasboas, no processo de responsabilidade a que foi submetido por acto da presidencia da mesma provincia de 12 de fevereiro de 1868. Salvador: Typographia Constitucional de França Guerra. 1868. 